\title{
Cerebrovascular Disorder
}

National Cancer Institute

\section{Source}

National Cancer Institute. Cerebrovascular Disorder. NCI Thesaurus. Code C2938.

A disorder resulting from inadequate blood flow in the vessels that supply the brain.

Representative examples include cerebrovascular ischemia, cerebral embolism, and cerebral infarction. 